\title{
CAPÍtulo vi \\ IMPORTANCIA DE LA CÁTEDRA DE CULTURA TEOLÓGICA EN EL CONTEXTO UNIVERSITARIO
}

\author{
José de Jesús Prada Valenzuela ${ }^{1}$
}

Múltiples comprensiones, valoraciones y prácticas fundadas sobre lo religioso coexisten hoy en la aldea global. Esta situación constituye una oportunidad para el enriquecimiento mutuo si se eleva el horizonte de comprensión sobre el "ser de la religión". La coexistencia de la diversidad en materia religiosa constituye una excelente coyuntura que posibilita y genera el autocuestionamiento, el intercambio de visiones y la toma de posturas compartidas. Dado que este contexto está presente en la universidad ${ }^{2}$, resulta imperativo que ella — como centro de

1 Doctor en Teología de la Pontificia Universidad Javeriana y magíster en Teología Bíblica de la Pontificia Universidad Bolivariana. Anteriormente, en ese mismo claustro universitario, recibió los títulos canónicos de Licenciado y Bachiller en Teología. Se graduó como licenciado en Filosofía en la Universidad Santo Tomás. Ha sido profesor en el Seminario Mayor Arquidiocesano de Bucaramanga y en las Universidades Pontificia Bolivariana y Pontificia Universidad Javeriana.

2 Esta multiplicidad, tanto de agentes como de visiones, está presente en la universidad. Las preguntas y las respuestas sobre Dios y sobre las religiones están inmersas en la cotidianidad universitaria. Al tiempo que se da un proceso de desencantamiento de lo institucional se viene generando una búsqueda de lo religioso, más allá de las fronteras de lo confesional, como una experiencia mística y de sentido. Se observa una especie de inquietudes religiosas en las nuevas generaciones. La manera como se abordan y resuelven 
formación y producción de pensamiento- ofrezca un espacio de reflexión riguroso, plural, abierto sobre el fenómeno religioso y sus diferentes manifestaciones, de tal manera que se pueda tener y ofrecer una visión seria y madura con la cual afrontar dicha diversidad asertivamente ${ }^{3}$.

De otra parte, en toda universidad que se precie de serlo, deberían existir espacios académicos de interlocución interdisciplinaria en donde se fortalezca el nivel de conciencia, la integridad y el respeto por la vida, la profesión propia y las de los otros; lugares de encuentro y apertura relacional en respeto e integridad en los cuales los conocimientos, las competencias y las técnicas se pongan en relación con la complejidad de los problemas sociales; problemas humanos que reclaman respuestas que provean esperanzas ciertas; indagación que exige cierto talante, profunda convicción interior, espiritualidad ${ }^{4}$.

Además, en los tiempos actuales, se está dando una vuelta vigorosa de lo religioso, de lo místico, de lo espiritual. Existe cansancio con el exceso de racionalización e instrumentalización propio de las sociedades complejas. En el ser humano existe cierta búsqueda persistente de algo más, de alguien más. Ya lo habían observado y puesto de presente las investigaciones de todos los autores clásicos de la sociología y la antropología: las creencias religiosas son elementos centrales de las culturas; su peso es decisivo en la construcción de las identidades de las personas y de los grupos.

En el horizonte descrito, claro que "tiene sentido hablar de lo religioso"s: toda universidad, con orientación secular o no, debe asumir de manera sistemática y rigurosa cuestiones como la existencia o no de Dios, el fin último del ser humano, el fundamento de la moral, son asuntos que todas las personas afrontan vitalmente en un momento o en otro y que merecen ser abordadas racionalmente en la universidad ${ }^{6}$.

determina el cómo de su futuro como personas y como colectivo. La doctrina configura la praxis. Así lo expresa el aforismo popular: aquello que crees determina como vives.

3 Jhon Sobrino, Inspiración cristiana de la universidad, en Universidad y sociedad, Hosrt Albach (y otros), (Bilbao: Universidad de Deusto, 1988), 316.

4 Guillermo León Zuleta Salas, Teología y Universidad. Cuestiones Teológicas, Vol. 40, N 94 (Bogotá, 2013), http://goo.gl/oFj3p9

5 Leonardo Boff, ¿Cuál es el lugar de lo religioso en el mundo? (S. f), http://goo.gl/TegKZV

6 Capellanía Universidad de los Andes, ¿¿Por qué se enseña Teología en la Universidad? (Santiago: Universidad de los Andes, 2012), http://goo.gl/8CX9hZ 
Dicho espacio académico, en varias universidades ya presente -al que se aludirá en este artículo con la categoría "Cátedra de cultura teológica”", debe integrar en su análisis crítico, entre otros, los siguientes aspectos: religión e historia; vaciedad e inmanencia; universidad y trascendencia; acción y sentido; vivir en paz; alentar la esperanza.

\section{Religión e historia}

Debido tanto a la pluralidad de acepciones existentes para el término "religión" como a la común comprensión existente que reduce el fenómeno religioso a su carácter institucional, el espacio universitario Cátedra de cultura teológica tendría que comenzar por abordar la esencia de la religión, sus elementos constitutivos fundamentales.

La multiplicidad de significaciones existentes para la voz "religión” puede estar relacionada, entre otros factores, con los mismos orígenes etimológicos de esta categoría. Su origen latino -no tiene equivalentes ni en el griego, ni en el hebreo- conecta con diversos vocablos que muestran distintos enfoques del ser y quehacer religioso ${ }^{8}$, desde aquellos para quienes lo más importante es la práctica cultual -pues su particular sensibilidad y horizonte de comprensión religiosa les posibilita en medio de ceremonias, cánticos y ritos litúrgicos sentirse plenamente conectados o con los demás seres o con el Ser Absolutamente Trascendente hasta aquellos para quienes lo más importante es la práctica de la justicia, los esfuerzos por transformar el mundo construyendo caminos y posibilidades de realización, felicidad y futuro para otros - pues situados en este lugar, entran en contacto profundo y consciente con la realidad de sí mismo, del mundo y de los otros encontrándose con el sentido de sí y de la existencia, y con ese ser tremendo y fascinante que les constituye en acto y en promesa.

7 Cultura teológica: espacio académico universitario de diálogo y confrontación de ideas que sin identificarse con sentimientos particulares, costumbres o creencias, y sin proselitismos o adoctrinamientos, busca acercarse a estos para analizarlos de una manera crítica, racional y éticamente responsable, observando, entre otros aspectos, la onticidad religiosa en el ser humano y las consecuencias que de allí se desprenden para la interrelacionalidad y la construcción de la historia (definición del autor).

8 Germán Marquínez Argote, siguiendo a Xavier Zubiri, señala cuatro tipos o maneras de quehacer la religión. 1. Enfoque ético: relegere (religar, reunir). 2. Enfoque ascético: reeligere (reelegir, conservar). 3. Enfoque numinoso: relinquere (respetar, reservar, apartar, no tocar). 4. Enfoque cultual: relegere (releer). Germán Marquínez Argote, Filosofía de la religión (Bogotá: Universidad Santo Tomás, 2012), 99-132. 
A lo largo de la historia, estos enfoques se han organizado de distintas formas ${ }^{9}$ y sus maneras de comprender, celebrar, valorar y afirmar (expresar) lo que perciben de sí mismos, del sentido de su existencia y del "ser y hacer" del Ser Supremo, también difieren. Sin embargo, en los diversos enfoques religiosos aparece -entre otros elementos comunes- la pretensión de servir como puente, camino, mediación para satisfacer esa necesidad de todo ser humano de conectarse, comunicarse profundamente con los otros seres y con ese Ser inmanente y trascendente, ese ser uno con todo y con todos y, a la vez, absolutamente otro.

Esa necesidad no es de unos determinados seres humanos o de unas determinadas épocas. El ser humano no logra sustraerse a esa profunda sed de comunicación que le define dentro de los diversos "phylums", no solo como ser racional sino también social, simbólico, político, cultural y religioso. Entre los animales conocidos y lo que conocemos de estos, solo el ser humano es capaz de religión ${ }^{10}$.

Podríamos ser muchos los que estemos en desacuerdo con determinados tipos de organización religiosa, pero no hay manera de ser areligiosos, o noreligiosos. Dado que somos animales humanos, y puesto que el animal humano, por ser humano, es ónticamente religioso, todo lo que hacemos y dejamos de hacer tiene un radical tinte religioso ${ }^{11}$. Luego, lo que correspondería es trabajar para transformarnos y perfeccionarnos. La cuestión no es pues de si religión o no religión, sino de cuál tipo de religión. Frente a los problemas, peligros o falencias que estamos percibiendo, encontrando o padeciendo al interior de las diversas religiones existentes, estamos obligados a revisar nuestras particulares maneras de ser religiosos optando por aquellas formas que nos hacen más personas, que nos de-liberan, que nos hacen más responsables con nuestro pasado, presente y futuro, en resumen, que nos comprometen en la construcción de la historia ${ }^{12}$.

9 Cualquier tipo de organización conlleva algún grado de institucionalidad.

10 “Ordo hominis ad deum” Tomás De Aquino, Summa Theologiae, II-II, q.81, a.1.

11 Karl Rahner, Curso fundamental sobre la fe, (Barcelona: Herder, 1979), 165.

12 Ciertamente, los vocablos que conforman el campo semántico "delibera" denotan la capacidad reflexiva del ser humano para contemplar y poner en diálogo diversos aspectos de un determinado campo de su realidad. Pero , la morfología de la palabra, conformada por la preposición "de" antepuesta a la red léxica conformada por el núcleo de significación común "libera" es particularmente sugerente y apropiada para poner de relieve la íntima coimplicación existente entre dicha capacidad reflexiva como condición necesaria para que la persona conociendo se conozca, se opte, se despliegue, se construya. 


\section{Vaciedad e inmanencia}

La humanidad entera vive tiempos críticos; sufre una grave carencia que está en contraste flagrante con su abundancia científica y tecnológica. El sistema de interdependencias tan complejo que constituye el milagro de la vida se encuentra hoy deteriorado y para algunos en riesgo de desaparecer. La naturaleza es frágil y limitada, y su capacidad de regeneración se encuentra amenazada. También el tejido de relaciones humanas se encuentra deteriorado; pareciese regido por la insensatez o la insolidaridad. Al organizar la existencia en un modelo cimentado en el egoísmo, los seres humanos se enfrentan entre sí y con lo que les rodea haciendo que peligre la supervivencia de los presentes y las futuras posibilidades de vida. Muchos, degradados a la condición de mercancías, compiten entre sí para vender su fuerza de trabajo a fin de seguir manteniendo una existencia reducida al consumo, a la producción, a la procreación. La mera razón instrumental conduce al sinsentido, a la vaciedad de la vida, a la angustia existencial. El encerramiento en el estrecho mundo del interés propio incapacita para trascender y vivir en comunión con los demás lugares, cosas y seres de la tierra. Se deteriora la naturaleza, la familia, la comunidad, se destruye la vida ${ }^{13}$.

Pero no hay consciencia sobre ello. Nuestra existencia histórica sigue siendo comprendida según el modo como se nos presenta y no como en realidad es. Nos fijamos en los eventos inmediatos más que en los elementos estructurales y las dinámicas que los producen. La propaganda diaria, los noticieros, la avalancha de distracciones y conversaciones nos ensordece. Al ocupar esos necesarios y escasos espacios de silencio y de tiempo nos incapacita para percibir lo que acontece en el fundamento de nuestro entramado social ${ }^{14}$.

13 José de Jesús Prada, "Amamos a los hermanos" vórtice del dinamismo soteriológico en 1 Juan (tesis doctoral, Pontificia Universidad Javeriana, 2011), 400-401.

14 "Actualmente nos encontramos con que la mayoría de nuestras concepciones están basadas en nuestros juicios e inclinaciones personales y del medio ambiente de nuestra sociedad. Es aterrador o debería ser aterrador cómo nos estamos quedando en lo superficial. Profundas y poderosas verdades, que cierto día descubrieron los grandes genios con padecer profundo e indecibles fatigas, se convierten en banales y superficiales cuando se las traduce al plano de nuestra discusión cotidiana. La tragedia es inevitable, pues no puede darse ninguna profundidad sin que se dé el camino que conduce a esa profundidad. La verdad está muerta si no existe el camino hacia la verdad; sin este, la verdad conduce solo a la superficie de las cosas. Solo podremos llegar a la verdad cuando nos preguntemos el por qué y el sentido de las cosas. Cuando analicemos y reflexionemos. No se llegara a la verdad únicamente a través de libros. La profundidad de pensamiento forma parte de la profundidad de la vida". Paul Tillich, La dimensión profunda. (Bilbao: Desclée, 1970), 107-124 
No captamos los corazones anhelantes de las masas, ni el espíritu ahincado de quienes tienen sensibilidad, para la hora histórica. Nuestros oídos están tan sordos a los gritos del estrato profundo de la sociedad como al clamor de la profundidad de nuestra alma. En la bulla de la vida diaria, abandonamos a las víctimas sangrientas de nuestro sistema social, desatendiendo su grito de auxilio, igual como lo hacemos con nuestra alma atormentada ${ }^{15}$.

Ahora bien, las épocas críticas pueden ser tiempos creativos ${ }^{16}$. Paradójicamente, cuando las condiciones son adversas, el ser humano puede crecer reconociéndose y desarrollando su capacidad de redescubrirse y de reinventarse. El hoy es propicio para que el ser humano rompa sus propios límites y se dé cuenta cuán religado, cuán unido de manera indisoluble se encuentra su destino a las circunstancias, condiciones y destino de su entorno y del ser de los otros seres -especialmente los que cree distintos- ${ }^{17}$.

Esta capacidad de salir de sí para encontrarse a sí mismo en los otros y en lo otro, descubriéndolos y descubriéndolo en lo propio, es capacidad de trascendencia: porque mueve, porque rompe, porque reconociendo lo dado y yendo más allá de ello, se hace cargo, constituyéndose proyecto siempre abierto, siempre finito e infinito, pues no encuentra del todo en este mundo el marco adecuado para su realización ${ }^{18}$.

15 Ibíd.

16 Leonardo Boff, La dignidad de la tierra (Madrid: Trotta. 2000), 11.

17 "En la noche que me envuelve, negra, como un pozo insondable, doy gracias al Dios que fuere por mi alma inconquistable. En las garras de las circunstancias no he gemido, ni llorado. Ante las puñaladas del azar, si bien he sangrado, jamás me he postrado. Más allá de este lugar de ira y llantos acecha la oscuridad con su horror. Pero no importa cuán recto haya sido el camino, ni cuantos castigos se lleven a la espalda: ningún otro es el amo de mi destino, ningún otro es el capitán de mi alma”. William Ernest Henley, Invictus. Poema tomado de la película Invictus. Clint Eastwood, 2009

$18 \mathrm{Al}$ respecto, Boff sostiene que llamamos trascendencia a lo que rompe, a lo que va más allá de lo dado en un proyecto infinito, pues no encuentra en este mundo el marco adecuado para su realización. Leonardo Boff, Tiempo de trascendencia, 41. Para llegar a ser uno mismo es preciso salir de la soledad del ensimismamiento. Se empieza a vivir de verdad cuando se sale del solipsismo del sí mismo para empezar para acontecer y auto comprenderse en la clave de un "nosotros" que abarca a todos e incluye, incluso, a la razón fundante, llámesele Dios, razón de vivir. Al hacerlo se refuerza aún más esa capacidad de darnos cuenta de lo que somos y por tanto de religarnos con el entorno, con los otros seres -especialmente los distintos- y con ese ser Absolutamente Otro y, sin embargo, cercano, solidario y fascinante. Cfr. Juan Manuel Roca, Cómo acertar con mi vida: la mirada del hombre ante su destino. (Navarra: EUNSA, 2013), 7. 
Son varios aquellos insatisfechos cuya sed de profundidad los hace buscar, indagar y, por ende, percibir la relevancia de reconocerse "ser religado". La trascendencia permite la emergencia de personas situadas, conscientes de los desafíos y oportunidades, capaces de encauzar estas variaciones de manera tal que naturaleza, mundo y sociedad -dadas o recibidas- sean cada vez más humanizadas ${ }^{19}$. Y, sin embargo, este viaje hacia el interior, hacia el misterio y el sentido de lo que "radicalmente se es", no resulta fácil. Inmersos en una cotidianidad marcada por urgencias insatisfechas, no pocos flotan irreflexivamente en la superficie de sus existencias, compitiendo desaforadamente por adquirir -cuando no acaparar- aquellos bienes y servicios ofertados y presentados por la mercadotecnia como vitales, como indispensables. Incapaces de romper el estrecho límite del "ser para sî", del "ser sin los otros" parecen no lograr captar la importancia de empezar a "ser con los otros", a "ser para los otros". Esta particularidad es descrita de manera magistral por Paul Tillich, cuando afirma:

Resulta cómodo vivir en la superficie mientras no sea esta objeto de una conmoción. Es doloroso abandonarla y bajar a fundamentos desconocidos. La gigantesca resistencia de todo ser humano, a fin de no afrontar el camino hacia la profundidad, y las múltiples excusas que se aducen para escapar de él, resultan totalmente naturales. La tortura de mirar hacia la propia profundidad es, para la mayoría de los hombres, insoportable. Prefieren retornar hacia la superficie sacudida y desértica de su vida y sus pensamientos anteriores. Lo mismo hay que decir de los grupos sociales, que echan mano a toda clase de ideologías y falsas razones para defenderse contra quienes pretenden llevarles por el camino que va hacia la profundidad de su existencia social. Tendrían por mejor tapar con pequeños remedios las hendiduras de la superficie, que no cavar hacia lo profundo. Los profetas de todo tiempo pueden hablar de la resistencia encarnizada que excitaron cuando se atrevieron a poner en manifiesto las profundidades de las crisis y la exigencia social ${ }^{20}$.

19 El mundo reclama urgentemente vida y paz, libertad y justicia; el mundo tiende inevitablemente a la unidad. Pedro Casaldáliga y José María Vigil, Espiritualidad de la liberación (Santander: Sal Terrae, 1992), 238.

20 Tillich, Op. Cit., 109. 


\section{Universidad y trascendencia}

El contexto universitario no es ajeno a esta situación. En su interior existen tendencias tecnócratas que con una visión focalizada olvidan que las múltiples causas de las dificultades que afrontamos exceden la ausencia de profesionales eficientes ${ }^{21}$. Esta mirada reduccionista -bastante simplista y facilista- pulula en la vida estudiantil trayendo profundas implicaciones sobre la construcción personal y el posterior desempeño profesional. También existen en la universidad los que estudian con la intención de ganar dinero con el menor esfuerzo, para llevar una vida cómoda en la cual se obtiene el disfrute inmediato del mayor placer con la mínima inversión. Absolutización del presente, libertad total y "todo vale" parecen constituir una especie de currículo oculto universitario con formas de socialización dominantes entre los diversos patrones de comportamiento y modos de valorar la realidad.

Tecnocracia, pragmatismo, inmediatismo y facilismo hacen aún más difícil ese gimnasio de la vida interior que conlleva un continuo y profundo contacto con la realidad de "lo que se es" y de "lo que acontece". Este contacto es lo que posibilita el permanente cuestionamiento y la construcción de respuestas a los asuntos centrales de la existencia, el por qué y para qué de lo que somos. Preguntas y respuestas que -aunque nunca finales ni dogmáticas- influyen y condicionan la manera de interrelacionarnos en lo ecológico, en lo político, en lo económico. Afrontar la cotidianidad vital como cuestión permanentemente abierta, junto con la manera de responderse, constituye, consciente o inconscientemente, el presente y el porvenir personal, familiar y colectivo que estamos y estaremos viviendo. Tal vez por ello, Martha Nussbaum, en su libro Sin fines de lucro: por qué la democracia necesita de las humanidades, señala como objetivos fundamentales de la educación, por encima de la preparación para un buen desempeño laboral, la formación para el ejercicio democrático y la incorporación de paradigmas que busquen "el sentido de la vida" ${ }^{22}$.

21 'The trouble isn't so much that we don't know enough, but it's as if we aren't good enough. The trouble isn't so much that our scientific genius lags behind, but our moral genius lags behind. The great problem facing modern man is that that the means by which we live have outdistanced the spiritual ends for which we live". "Rediscovering Lost Values". Sermón pronunciado en la Segunda Iglesia Bautista de Detroit (28 febrero 1954) por Martin Luther King, Jr. (American Baptist Minister and Civil-Rights Leader. 1929-1968), http://mlk-kpp01.stanford.edu/index.php/kingpapers/article/rediscovering_lost_values/

22 En un escrito inédito hasta hoy, Gerardo Martínez afirma: "El sistema quisiera hacer de la educación una herramienta para adherir cada vez más al estudiante a lo puramente inmanente, material, sensitivo y biológico, produciendo un tipo de personas cuyos proyectos de vida no apasionan ni invitan a "estar en el mundo" con dirección y horizonte. Cuyas existencias no mejoran ni producen cambio. 
Este concebir la educación en la perspectiva de indagación sobre el significado, tanto de la existencia humana como de las consecuencias de su acción, resulta coincidente con el rol del espacio universitario, aquí designado con la categoría cátedra de cultura teológica, espacio para descubrir, por una parte, la relevancia de reconocernos como seres "de sentido", abiertos, religados, trascendentes y, por otra, el hecho de que lo religioso es dimensión constitutiva humana, cuyo cuidado y buen manejo es fundamental para el crecimiento personal, familiar y social.

En el mundo actual, no hay nada tan urgente como apreciar en su justo punto la eficacia social de lo religioso, reivindicar su valor transformador: para que se logre un cambio radical del mundo no hay nada tan urgente como cambiar la espiritualidad de las personas. No se trata de cómo imaginamos a Dios, sino del papel que esa imagen desempeña en nuestra convivencia. La vida, la suerte, la felicidad o la postración de un colectivo depende de la imagen de Dios, que por tradición y costumbre, de padres a hijos, de generación en generación, nos vamos entregando acríticamente, como un paquete incuestionable que exigiría sumisión completa e indubitable, y que como fácilmente se puede ver, condiciona gravemente nuestras relaciones sociales y nuestra relación con la historia y con la naturaleza. Tan trabado está el concepto de Dios con nuestra vida, con nuestras religiones y con nuestra sociedad que el poeta Casaldáliga cree que solo cambiando la comprensión sobre Dios serán viables los demás cambios: "Para cambiar la vida hay que cambiar de Dios. Hay que cambiar de Dios para cambiar la historia. Para cambiar el mundo hay que cambiar de Dios. ¿Por qué no cambias de Dios?”23.

Contrariamente a lo anterior, la educación está hecha para desapegarnos de nosotros mismos y de nuestro mundo egoísta. Está hecha para lanzarnos y construirnos como lo que somos, seres personales con vocación a una existencia con sentido y felicidad". En ese mismo sentido, para Marta Nussbaum, si las sociedades quieren ser y conservarse como sociedades democráticas debe formar a todos sus ciudadanos, tanto en la escuela como en la Universidad, fundamentalmente, en las ciencias humanísticas. Martha Nussbaum, Sin fines de lucro: por qué la democracia necesita de las humanidades, Signo y Pensamiento, Vol. XXX, $\mathrm{N}^{\circ}$ 58, (2011): 16-22.

23 Lourdes Celina Vázquez Parada y Wolfgang Vogt, La idea de Dios en Guadalajara: diversos caminos hacia el conocimiento de un mismo Dios (Guadalajara: Editorial Universitaria-Universidad de Guadalajara, 2011), 7 


\section{Acción y sentido}

La cátedra de cultura teológica cumple con este rol y esta misión en la universidad, si posibilita el que los educandos puedan reconocer la importancia de cultivar y acrecentar su vida interior impregnando el mundo de su cotidianidad con la impronta de lo humano, asumiéndolo en un horizonte de sentido y actuación:

El centro del quehacer educativo no es el hombre sin sentido de lo absoluto y, por lo tanto, sin sentido de sí mismo. Decir persona es decir trascendencia e implica situarse más allá, en otro nivel ontológico en el que ser y valor adquieren un nuevo sentido en la búsqueda de un bien. Ser persona es una aventura peligrosa y difícil, pero enriquecedora y definitiva, gozosa y plena. La educación, cuando conserva su sentido, promueve esta aventura. Cuando no la promueve pierde su razón de ser, su sentido. ${ }^{24}$

Para esto, el espacio de cultura teológica, con sus diversos contenidos temáticos y procesos pedagógicos, presentando una postura abierta y crítica del fenómeno religioso, debe posibilitar que el estudiante busque caminos para adentrarse cada vez más en la profundidad vital que emerge en la interioridad de los otros, en la interioridad del mundo, en la interioridad de sí. ${ }^{25}$

A través del conocimiento y la discusión amplia alrededor de variadas temáticas del campo religioso, observando las diversas concepciones religiosas, en medio de un análisis argumentativo — respetuoso, sí, pero sin caer en el "todo vale" — la cátedra de cultura teológica posibilitaría el que los participantes realizasen su propio camino de comprensión de la existencia, captando el sentido profundo de lo que son, personas coresponsables de la construcción de historia y de mundo.

Este sentido trasciende los límites inmediatos de la realidad personal y social, en aras de encontrar la significación superior del por qué y para qué existir, formarse profesionalmente, cumplir un rol en la familia, en la ciudad, en el país que se habita, siendo mejores seres humanos más compasivos, más humildes, más sencillos, más solidarios, más responsables, más felices ${ }^{26}$.

24 Ciro Schmidt, Hermenéutica analógica como paradigma educativo, Analogía Filosófica, $\mathrm{N}^{\circ}$ 28, (2011), 38.

25 Boff, hablando del rol de las religiones en la vida de sus seguidores afirma: "Las religiones cumplen su misión cuando suscitan y alimentan la vida interior de sus seguidores, cuando les ayudan a hacer el viaje a su interior, rumbo al corazón, donde habita el Misterio". Leonardo Boff, La dimensión olvidada: la vida interior, (América Latina en movimiento, 2008), http://goo.gl/RXQQn5

26 Aquí bien podrían parafrasearse algunas de las afirmaciones de Enrique Martínez: A la hora de la verdad, para Jesús de Nazareth, lo que cuenta es la compasión hacia el ser humano. El mensaje de varias de sus parábolas me recuerda la respuesta del Dalai Lama a la pregunta sobre cuál era la mejor religión: "la que 
De esta manera el espacio de cultura teológica contribuiría para que en la Universidad -sin descuidar la transmisión y creación de conocimientos y experiencias sobre el ser y el funcionamiento de los seres y las cosas - los miembros de la comunidad universitaria sean capaces de indagar por el secreto de la existencia humana, escudriñar el para qué se vive, encontrar en ese para qué el sentido de lo que hacemos ${ }^{27}$.

\section{Vivir en paz}

Las religiones son más que simples textos o tratados filosóficos. No existen en sí, independientes de sujetos, sociedades y personas. Existen individuos concretos aunados en grupos religiosos con creencias profundas que generan motivaciones, estilos de vida y acción que se enraízan en los afectos y en los imaginarios; existen instituciones religiosas cuya incidencia es decisiva en los procesos de reconciliación personal y social, en la implementación de prácticas ecológicas, en la educación para el cumplimiento y el respeto de los deberes y de los derechos humanos ${ }^{28}$.

En un mundo en el que hábitos mentales, prácticas, conceptos y expresiones están puestos en cuestión, por y para algunos ${ }^{29}$, la religión se muestra como elemento de cohesión social y construcción personal; sobrepasando los límites territoriales y las razas aúna grupos de diversos

hace mejores personas. La que te hace más compasivo, más sensible, más desprendido, más amoroso, más humanitario, más responsable. Tu práctica religiosa no es un túmulo al Dios vivo solo cuando te transforma en un mejor ser humano. La religión está relacionada con aquellas cualidades del espíritu humano como el amor, la compasión, la paciencia, la tolerancia, la capacidad de perdonar, la alegría, la responsabilidad, la armonía. Cfr. Enrique Martínez Lozano, En dónde están las raíces. (Madrid: Narcea, 2006), 162-163. Al momento de ir a este autor, nótese que la paráfrasis aquí hecha dista del maniqueísmo en el que cae dicho autor, distinguiendo con Boff entre lo bueno, la espiritualidad, y lo malo, la institución religiosa.

27 Según Dostoievski, el secreto de la existencia humana está no solo en vivir, sino también en saber para qué se vive, y en este para qué se encuentra el sentido de lo que hacemos. Proverbia, Citas y frases célebres http://goo.gl/XrxqZx

28 Gabriel Izquierdo Maldonado, Religiones, sociedad y persona. Revista Javeriana, T. $141 \mathrm{~N}^{\circ} 716$, (2005): 35-37.

29 Los moldes culturales de significación y de sentido están rotos. Lo antiguo no vale. Lo nuevo carece de figura. Andrés Torres Queiruga, Fin del cristianismo premoderno (Santander: Sal Terrae, 2000), 117. 
estados, ofreciendo pasado, raigambre, identidad, ideales de vida y sentidos de acción ${ }^{30}$. Sin embargo, ciertos fundamentalismos que tienen claros nexos con tradiciones religiosas surgen o parecen resurgir.

Al final del siglo pasado y en estas dos primeras décadas del presente, dos civilizaciones, la occidental y la islámica, parecen chocar con violencia. Los conflictos económicos y políticos en Irak, Afganistán, Libia, Siria y actualmente en el Estado Islámico son vistos por cierta franja de la población mundial como un choque de civilizaciones en clave religiosa. ¿Constituyen las religiones un factor de violencia $y$, por ende, una grave amenaza para la actual y futura convivencia en paz dentro de una aldea global pluriforme, diversa y sin embargo una? ${ }^{31}$

Este contexto es decisivo para los acentos, matices y estilos con los cuales y desde los cuales se aborde la construcción del espacio universitario nominado como cátedra de cultura teológica. En un marco de respeto y racionalidad, hay que interrogar seriamente — sin temores ni falsos respetos - sobre lo que se está haciendo y lo que se debería hacer en las distintas religiones a fin de contrarrestar todo clima de intolerancia, dogmatismo, violencia, etc.

Este ejercicio académico exige abordar la discusión teórica sobre lo específico de cada tradición religiosa. El enfoque de dicho ejercicio tiene que ser, por su naturaleza, plural y contextual, encarnado en las realidades. No es un espacio para hacer proselitismos y, sin embargo, es un espacio en el que deben reconocerse, con gratitud, los diferentes aportes realizados por las diversas religiones, cada vez que alguien, inspirado por esta, ha encarado asertivamente las acuciantes problemáticas o desafíos afrontados por la humanidad en su época ${ }^{32}$.

La historia de las relaciones entre las diversas religiones puede ser vista como un entramado de relaciones conflictivas. Es cierto que las personas de civilizaciones diferentes tienen diferentes conceptos sobre el trato debido a la mujer, las relaciones entre Dios y el hombre, el individuo y el grupo, los padres y los hijos, o las formas de gobierno existentes, por señalar al menos unas. Pero las diferencias no entrańan necesariamente conflicto y los conflictos no implican necesariamente

30 Samuel Huntington, El choque de civilizaciones y la reconfiguración del orden mundial (Barcelona: Paidós, 1997), 53-54.

31 José de Jesús Prada Valenzuela, Cierta ilógica egonómica: una lógica de muerte que reta a la unidad interreligiosa, Temas Vol. 3, N 1 (octubre de 2007), 145-154.

32 Casar a Dios con la propia teovisión —esperar de Él justicia retributiva y vindicativa, intentar secuestrar su ser y su acción mediante ritos y prácticas - sigue siendo una tentación presente en los seres humanos de los diversos grupos culturales hoy existentes. 
violencia. Los valores no se imponen; se proponen, se muestran, se comparten. La diferencia no legitima la agresión ${ }^{33}$.

Si se quiere futuro, es necesario deslegitimar el enfrentamiento: ninguna guerra es justa; ninguna guerra es santa; ninguna guerra es razonable. Como tampoco es justo o legítimo aspirar a imponer la propia visión como universal. Lo viable, lo humano, lo religioso, es aprender a coexistir constructivamente con los “otros" en un mundo unido pero no uniforme. El diálogo y el aprecio mutuos son posibles si se trabaja aunando esfuerzos para enfrentar diferentes urgencias, en especial la construcción de otro tipo de relaciones entre los seres humanos y de estos con la naturaleza ${ }^{34}$.

Las perspectivas del trabajo interreligioso son oportunas para el mapa geopolítico actual. Poco a poco se va logrando que las personas de las distintas confesiones religiosas reconozcan la libertad de Dios para amar y actuar en y por fuera de la propia confesionalidad. Está cerca el día en que las personas de las diversas religiones del mundo comprendan y trabajen al interior de su propia institucionalidad religiosa para que se entienda que las diversas religiones son diversos 'rostros' o expresiones de la misma experiencia religiosa humana, la cual es al mismo tiempo una y multiforme: la salvación viene realizada por Dios en quien Él lo desee y por caminos extraordinarios que solo Él conoce ${ }^{35}$.

En este orden de ideas, el espacio universitario cátedra de cultura teológica sería un espacio de diálogo y trabajo interreligioso, en el cual el énfasis estaría puesto en el proceso de reconocer en la pluralidad del fenómeno religioso esos elementos articuladores fundantes relacionados con la promoción de la vida y de las condiciones que esta requiere para preservarse y desplegarse, entre ellos, la convivencia respetuosa y armónica: que cada quien se reconozca ciudadano, necesitado de los otros, agente mediador y coresponsable de la construcción de unas relaciones fraternas, solidarias y en paz.

33 Prada Valenzuela, Op. Cit., "Cierta ilógica egonómica: una lógica de muerte que reta a la unidad interreligiosa", 145-154.

34 Ibíd.

35 La convergencia y pluralidad de cosmovisiones en un mismo espacio de diálogo y trabajo interreligioso exige y posibilita espacios para reconocer diversas experiencias religiosas en la búsqueda común del Absoluto"; para aceptar la distancia entre cualquiera de éstas (aún la propia) y la realidad de ese Ser Absolutamente Inmanente y Trascendente cuyo misterio no se agota en ninguna de las comprensiones humanas; para asumir la inseguridad, perfectibilidad y falibilidad propias de cualquier proyecto, institucionalidad o constructo humano; distinguir entre lo esencial y lo no esencial en un ángulo no imperialista, más abierto, menos dogmático. En fin, espacios para -sin negar lo distinto y sin dejar de ser sí mismo- apreciarse y conservarse creciendo al contacto con lo extrańo, superando los límites de lo propio. Ibíd. 


\section{Alentar la esperanza}

Finalmente, la religión contiene una enorme fuerza constructora para el presente del individuo y de la colectividad. En ella reside una inquebrantable esperanza para el futuro de una humanidad golpeada por el sufrimiento y la muerte. La religión alienta la esperanza y sostiene la lucha cotidiana incesante para lograr un mayor crecimiento "humano" y un mayor bienestar familiar y social. Frente a múltiples propuestas contemporáneas que propenden por un vaciamiento del significado de la vida, en el cual prevalece una visión desesperanzadora acerca de nuestro presente y posterior desenlace, la religión ofrece a una perspectiva esperanzadora respecto de las diversas realidades que rodean a los seres humanos, así como de su misma condición ${ }^{36}$. Esperanza con anclaje en las realidades que afrontamos, pero siempre abierta a posibilidades de trascendencia y transformación aún no percibidas. Esperanza con fuerza que impulsa a salir de sí mismo y a realizar acciones concretas en pro del bienestar común.

36 No entiendo la existencia humana y la necesaria lucha por mejorarla sin la esperanza y sin el sueño. La esperanza es una necesidad ontológica; la desesperanza nos inmoviliza y nos hace sucumbir al fatalismo en el cual no es posible reunir las fuerzas indispensables para el embate recreador del mundo. La sola esperanza no transforma el mundo pero sin ella la lucha flaquea, titubea. Necesitamos la esperanza como el pez necesita del agua incontaminada. Paulo Freire, Pedagogía de la esperanza, (México: Siglo XXI, 2002), 8 . 


\section{Referencias}

Aquino, Tomás de. Summa Theologiae, II-II, q.81, a.1.

Boff, Leonardo. La dignidad de la tierra. Madrid: Trotta. 2000.

Boff, Leonardo. ¿Cuál es el lugar de lo religioso en el mundo? (S. f). http://goo.gl/TegKZV

Boff, Leonardo. La dimensión olvidada: la vida interior. América Latina en movimiento, 2008. http://goo. gl/RXQQn5

Capellanía. Universidad de los Andes, ¿Por qué se enseña teología en la Universidad? Santiago: Universidad de los Andes, 2012. http://goo.gl/8CX9hZ

Casaldáliga Pedro y José María Vigil. Espiritualidad de la liberación. Santander: Sal Terrae, 1992.

Eastwood, Clint. Invictus. 2009.

Freire, Paulo. Pedagogía de la esperanza. México: Siglo XXI, 2002.

Huntington, Samuel. El choque de civilizaciones y la reconfiguración del orden mundial. Barcelona: Paidós, 1997. Izquierdo Maldonado, Gabriel. Religiones, sociedad y persona. Revista Javeriana. T. $141 \mathrm{~N}^{\circ}$ 716, (2005): 35-37.

Luther King, Jr., Martin. Sermón pronunciado en la Segunda Iglesia Bautista de Detroit (28 febrero 1954) por (American Baptist Minister and Civil-Rights Leader. 1929-1968). http://mlk-kpp01.stanford. edu/index.php/kingpapers/article/rediscovering_lost_values/

Marquínez Argote, Germán. Filosofía de la religión. Bogotá: Universidad Santo Tomás, USTA, 2012.

Martínez Lozano, Enrique. En dónde están las raíces. Madrid: Narcea, 2006.

Nussbaum, Martha. Sin fines de lucro, por qué la democracia necesita de las humanidades. Signo y Pensamiento. Vol. XXX, № 58 (2011): 16-22.

Prada Valenzuela, José de Jesús. Cierta ilógica egonómica: una lógica de muerte que reta a la unidad interreligiosa, Temas Vol. 3, N¹(octubre de 2007): 145-154.

Prada, José de Jesús. "Amamos a los hermanos” vórtice del dinamismo soteriológico en 1 Juan.Tesis Doctoral, Pontificia Universidad Javeriana, 2011.

Proverbia. Citas y frases célebres. http://goo.gl/XrxqZx

Rahner, Karl. Curso fundamental sobre la fe. Barcelona: Herder, 1979.

Roca, Juan Manuel. Cómo acertar con mi vida: la mirada del hombre ante su destino. Navarra: EUNSA, 2013.

Schmidt, Ciro. Hermenéutica Analógica como paradigma educativo. Analogía Filosófica, No 28 (2011).

Sobrino, Jhon Inspiración cristiana de la universidad. En Universidad y sociedad, Hosrt Albach (y otros). Bilbao: Universidad de Deusto, 1988.

Tillich, Paul. La dimensión profunda. Bilbao: Desclée, 1970.

Torres Queiruga, Andrés. Fin del cristianismo premoderno. Santander: Sal Terrae, 2000. 
Vázquez Parada, Lourdes Celina y Wolfgang Vogt. La idea de Dios en Guadalajara: diversos caminos hacia el conocimiento de un mismo Dios. Guadalajara: Editorial Universitaria-Universidad de Guadalajara, 2011.

Zuleta Salas, Guillermo León. Teología y Universidad. Cuestiones Teológicas, Vol. 40, № 94 . Bogotá, 2013. http://goo.gl/oFj3p9 